\title{
陰イオン交換/吸光光度法による環境物質中の 微量スズの定量
}

\author{
黒出 六郎®, 林 部 豊, 小熊 幸一* \\ (1987 年 6 月 20 日受理)
}

\begin{abstract}
$\mathrm{Sn}(\mathrm{IV})$ は $0.25 \mathrm{M}$ 又は $0.05 \mathrm{M}$ シュウ酸共存下, $0.005 \sim 2 \mathrm{M}$ 硫酸溶液より，強塩基性陰イオン交 換樹脂 Bio- Rad AG 1 亿強く吸着する. 特に硫酸 $0.5 \mathrm{M}$ 以下では分布係数は $10^{3}$ 以上に達し, $\mathrm{Sn}$ (IV) の分離濃縮法として有用であるので，本系を生物試料などの中の Snの定量に適用した。すなわち試料 を硫酸と硝酸（フッ化水素酸併用）で分解し， $0.5 \mathrm{M}$ 硫酸- $0.05 \mathrm{M}$ シュウ酸溶液として上記樹脂の小カ ラムに Sn を捕集後溶離し，ピロカテコールバイオレットによって定量した．この方法を国立公害研究 所の環境標準試料, 頭髮, ムラサキイガイ, 池底質に適用したところ, 分析值は既報值とよく一致し, 相対標準偏差は Sn $1 \mathrm{ppm}$ レベルで 2〜4\%，10 ppm レベルで 1\% となり，高感度・高精度で $\mathrm{Sn}$ 定量することができた。
\end{abstract}

\section{1 緒䓂}

環境試料中の微量の Sn は, 分光分析法, NAA, 吸光 光度法, ポーラログラフィー, AAS など種々の方法に より定量されている1).

このうち, Sn の吸光光度法についてはフェニルフ ルオロン, ジチオール， ピロカテコールバイオレット (PV) が広く使われている(2)3)が，PV は比較的強い酸性 条件に打いて水に可溶な $\mathrm{Sn}(\mathrm{IV})$ 錯体を生成し, 保護 ロイドを必要としない高感度試薬として知られている. しかし若干の妨害元素があり，環境試料分析に用いる場 合には, ヨウ化物抽出(4), $N$-ベンゾイル-N-フェニルヒド ロキシルアミン抽出 ${ }^{5)}$, ジチオール含浸ポリウレタンフ オームカラムを用いるカラム抽出クロマトグラフィー6) などが Snの分離に利用されている。一方，児玉らマは 塩酸系陰イオン交換により, 海水中の Sn を濃縮分離し ている. しかし，底質試料や生物試料は硫酸を主体とし て分解することが多いので，硫酸を含む系より Sn を直 接陰イオン交換樹脂に捕集できれば便利である.

本報では硫酸にシュウ酸を加えた溶液系よりSnを才 クザラト錯体としてイオン交換樹脂に捕集することを試 みたところ，分離濃縮系として優れていることを見いだ したので，これをPV 法と組み合わせ，環境物質中の微 量 Snの定量に適用した。環境標準試料に適用して満足

* 千葉大学工学部分析化学教室 : 260 千葉県千葉市 弥生町 1-33
すべき結果を得たので報告する。

$$
2 \text { 実験 }
$$

\section{1 試 薬}

スズ標準溶液: AAS 用スズ標準溶液 $\left(1.00 \mathrm{mg} \mathrm{ml}^{-1}\right.$, $3 \mathrm{M}$ 塩酸酸性, 関東化学製) を所定量分取し, 硝酸と硫 酸とを加え硫酸の白煙が生ずるまで加熱湛縮した後希硫 酸で希釈して $200 \mu \mathrm{g} \mathrm{Sn} / \mathrm{ml}$ の $3 \mathrm{M}$ 硫酸酸性溶液を調 製した。必要に応じてこの溶液を希釈し， $0.5 \mathrm{M}$ 硫酸溶 液として使用に供した。

$\mathrm{PV}$ 溶液: $1.0 \times 10^{-2} \mathrm{M}$ 水溶液を調製し, 使用の際水 で $7.5 \times 10^{-4} \mathrm{M}$ に希秎した。

塩化セチルトリメチルアンモニウム（GTAG）溶液： $3.0 \times 10^{-3} \mathrm{M}$ 水溶液を調製し, 水で $7.5 \times 10^{-4} \mathrm{M}$ に希 釈して使用した。

眽酸ナトリウム一塩酸綑衝溶液：1 M 酢酸ナトリウム 溶液と $1 \mathrm{M}$ 塩酸を混合し, $\mathrm{pH} 1.6$ とした。

イオン交換樹脂 : 強塩基性陰イオン交換樹脂 Bio-Rad AG 1-X8, Cl- 形, 100〜200 メッシュを大型カラムに 詰め, $1 \mathrm{M}$ 硫酸を十分流して $\mathrm{SO}_{4}{ }^{2-}$ 形に変元た. 水洗 後 $50^{\circ} \mathrm{C}$ で 4 時間乾燥し, 臭化カリウム飽和溶液を入 れたデシケーター中に保存した。

全実験を通じ特級試薬と蒸留一脱塩水を使用した。

\section{2 装 置}

日立 $220 \mathrm{~A}$ 型ダブルビーム分光光度計に光路長 $1 \mathrm{~cm}$ の角型ガラスセルを装着して吸光度を測定した.

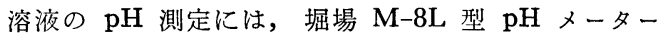
と S815-1 型 $\mathrm{pH}$ 複合電極を使用した。

イオン交換カラムは, 内径 $8 \mathrm{~mm}$ のフィルター付き ガラス製クロマトカラムに $2 \mathrm{~g}$ の陰イオン交換樹脂を詰 
め，樹脂柱尚さ $40 \mathrm{~mm}$ として用いた。

\section{$2.3 \mathrm{Sn}$ の分布係数 $K_{\mathrm{d}}$ の測定}

バッチ法により測定した. $50 \mathrm{ml}$ 共栓三角フラスコに $1 \mathrm{~g}$ の陰イオン交換樹脂を量り取り, $27 \mu \mathrm{mol}$ の Sn を 含む種々の濃度の硫酸ーシュ.酸溶液 $40 \mathrm{ml}$ を加光た後 $25^{\circ} \mathrm{C}$ で 20 時間振り混ぜる.

相分離後次式により $K_{\mathrm{d}}$ を算出した.

$$
K_{\mathrm{d}}=\frac{\text { 樹脂中の } \mathrm{Sn} \text { の量/樹脂の重さ }(\mathrm{g})}{\text { 溶液中の } \mathrm{Sn} \text { の量/液相の体積 }(\mathrm{ml})}
$$

な戚溶液は, シュウ酸濃度 $0.05 \mathrm{M}$ 及び $0.25 \mathrm{M}$ のそ れぞれに対し, 硫酸濃度を $0.005,0.015,0.025,0.05$, $0.15,0.25,0.5,1.0,2.0 \mathrm{M}$ と変元て調製した.

\section{4 分析法}

2.4.1 試料の分解 生物試料 $(2 \mathrm{~g})$ を量り取り, 常 法8) に上り硫酸と硝酸により分解，フッ化水素酸処理を 加光, 最終的に $0.5 \mathrm{M}$ 硫酸 $-0.05 \mathrm{M}$ シュウ酸溶液 100 $\mathrm{ml}$ とする。底質試料は $0.5 \mathrm{~g}$ を採り，土壤分解法9 に 準じ, 硫酸-過塩素酸一フッ化水素酸に上り分解し, 蒸発 乾固後硫酸で処理し, 同じく $100 \mathrm{ml}$ の $0.5 \mathrm{M}$ 硫酸一 $0.05 \mathrm{M}$ シュウ酸溶液とする.

2.4.2 Sn の濃縮・定量 上述の溶液をイオン交換 カラムに $1.5 \mathrm{ml} \mathrm{min-1}$ の流量で負荷し, Snを吸着さ せる. $0.5 \mathrm{M}$ 硫酸 $-0.05 \mathrm{M}$ シュウ酸溶液でカラムを洗 浄し, 次いで $3 \mathrm{M}$ 塩酸 $-1 \%$ アスコルビン酸溶液 $(60$ 。 C) $20 \mathrm{ml}$ により $\mathrm{Ti}(\mathrm{IV}), \mathrm{Zr}(\mathrm{IV}), \mathrm{Fe}(\mathrm{III}, \mathrm{II})$ を溶 離与る。次に $0.5 \mathrm{M}$ 硫酸 $-0.3 \%$ 過酸化水素溶液 $\left(60^{\circ}\right.$ C) に上り $\mathrm{Sn}(\mathrm{IV})$ を溶離する，始めの流出液 $7 \mathrm{ml}$ を 捨て, 続く $15 \mathrm{ml}$ を捕集し, これに硝酸 $2 \mathrm{ml}$, 過塩素 酸数滴を加兄て被発し, 白煙に至らしめる. 放冷後 0.5 $\mathrm{M}$ 硫酸 $1 \mathrm{ml}, 7.5 \times 10^{-4} \mathrm{M} \mathrm{PV} 1 \mathrm{ml}, 7.5 \times 10^{-4} \mathrm{M}$ CTAC $1 \mathrm{ml}$, 酢酸ナトリウム塩酸緩衝溶液 $5 \mathrm{ml}$ を加 光, $2 \mathrm{M}$ 酶酸ナトリウムで $\mathrm{pH}$ を $1.6 \pm 0.1$ に調節す る. これを $25 \mathrm{ml}$ イスフラスコに移し, 水で定容とし た後, 試楽から試験液を刘照として $662 \mathrm{~nm}$ における吸 光度を測定する。

\section{3 結果と考祭}

\section{1 硫酸-シュウ酸系における Sn の陰イオン交換}

イオン交換による Sn の濃縮法として提案されている 方法は少ない，海水を $2 \mathrm{M}$ 塩酸として $\mathrm{Sn}$ を陰イオン 交換樹脂に濃縮する方法が報告されているが，塩酸系は 選択性に乏しいので， Fe，Mo などを除くため第二段の
陰イオン交換が必要である7)、硫酸ーシュウ酸系からの Sn の陰イオン交換については報告はないが, 䜖酸ーシュ ウ酸系 ${ }^{10)}$ に比し,ク口ロ錯体の吸着寄与がないため, 選択 性は高い.シュウ酸浱度を $0.05 \mathrm{M}$ 又は $0.25 \mathrm{M}$ とし て硫酸濃度を変光て, Bio-Rad AG 1 ( $\left.\mathrm{SO}_{4}{ }^{2-}\right)$ に対す る $\mathrm{Sn}(\mathrm{IV})$ の分布係数 $K_{\mathrm{d}}$ を測定した結果を Fig. 1 に示す. 硫酸 $0.5 \mathrm{M}$ 以下では $10^{3}$ 以上の $K_{\mathrm{d}}$ が見ら れ, 本系はS n を濃縮するのに十分な特性を示す. 生物 系試料を硫酸を含む混酸で分解した後, 硫酸の水溶液を 調製するときの便宜を考光，本報では $0.5 \mathrm{M}$ 硫酸-0.05 Mシュウ酸系より Sn を濃縮することとした．この条件 下では $\operatorname{Sn}(\mathrm{IV})$ の分布係数は 1000 で, $1.0 \mathrm{M}$ 塩酸 -0.05 $\mathrm{M}$ シュウ酸系の值 $\left.{ }^{10}\right)>10^{4}$ よりはるかに低く, 溶離条件 を見いだすことは比較的容易である。

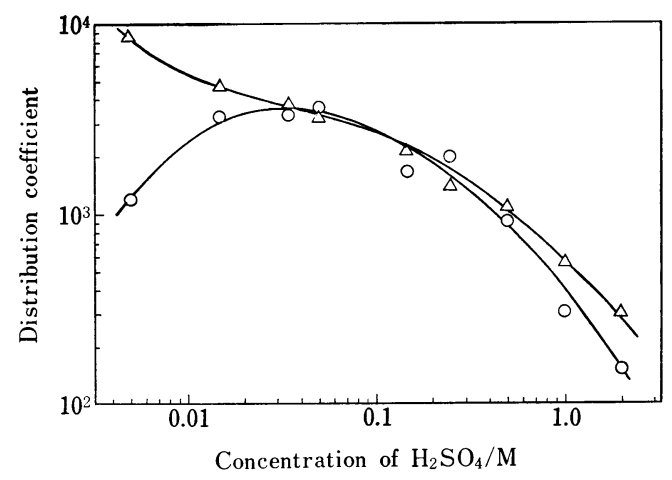

Fig. 1 Distribution coefficients of $\mathrm{Sn}(\mathrm{IV})$ on Bio$\mathrm{Rad}$ AG 1-X8 $\left(\mathrm{SO}_{4}{ }^{2-}\right)$ in sulfuric acidoxalic acid media

Oxalic acid : $\triangle 0.05 \mathrm{M}, \bigcirc 0.25 \mathrm{M}$

アルカリ，アルカリ土類，二価重金属， $\mathrm{Al}$ などは 本系よりカラムに吸着しないが, 多価金属イオン Mo $(\mathrm{VI}), \mathrm{Ti}(\mathrm{IV}), \mathrm{Zr}(\mathrm{IV}), \mathrm{Sb}(\mathrm{III})$ は強く吸着する, $\mathrm{Fe}$ （III） 溺い吸着を示すが，実質的にはシュウ酸により 光の存在下で還元された $\mathrm{Fe}(\mathrm{II})$ の寄与と思われる. Fe を含むこれらの吸着元素群は PV 法で著しい妨害元素 となるので, クロマト的にこれらをカラムより溶出分 離することを試みた。 このらち $\mathrm{Ti}(\mathrm{IV}), \mathrm{Zr}(\mathrm{IV}), \mathrm{Fe}$ (III) は $3 \mathrm{M}$ 塩酸 ( $1 \%$ アスコルビン酸を含む)により 容易に溶出する. $\mathrm{Sn}(\mathrm{IV})$ は $0.5 \mathrm{M}$ 硫酸により容易に 溶離されるが, Mo(VI) は過酸化水素 $(0.3 \%)$ の涯加 によりカラムに保持される。このとき, $\mathrm{Sb}(\mathrm{III})$ の一部 は溶出するが, PV 法で $\mathrm{Sn}(\mathrm{IV})$ と同量存在して $3 \%$, 10 倍量存在して $30 \%$ の正誤差を与えるのみであり，か 
つケイ酸塩岩石，生物試料中の $\mathrm{Sb}$ の量は Sn の含有量 をはるかに下まわるので11)，特別の場合を除き無視する ことができよう。

\section{2 環境標準試料中の Sn の定量}

Table 1 に Sn の標準溶液及び一定量の $\mathrm{Sn}$ を含む 合成試料について，2.4.2 の方法に従いSn を分離定量 した結果を示す．合成試料は, NBS の Bovine Liver 及び Orchard Leaves の無機主成分組成（両者の平均 值)を模して調製したもので，これにPVによる吸光光 度定量の妨害となる $\mathrm{Ti}$ 及び Mo を添加したものであ る. いずれも $100 \mathrm{ml}$ 中 $5 \mu \mathrm{g}$ の $\mathrm{Sn}(\mathrm{IV})$ について回収 をみたものである，回収は定量的であり，硫酸ーシュウ 酸系陰イオン交換が微量 $\mathrm{Sn}$ の濃縮に効果的であること が分かる.

この方法を国立公害研究所の 標準試料, 頭髮, ムラ サキイガイ，池底質中の Sn の定量に適用した結果を

Table 1 Anion-exchange separation of $\mathrm{Sn}$ in $0.5 \mathrm{M}$ sulfuric acid- $0.05 \mathrm{M}$ oxalic acid media $(100 \mathrm{ml})$

\begin{tabular}{|c|c|c|}
\hline Sample & 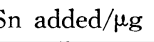 & Sn found $/ \mu \mathrm{g}$ \\
\hline Sn(IV) alone & 5.0 & $\begin{array}{l}5.15,4.93,5.13 \\
\quad(\text { av. } 5.07 \pm 0.12)\end{array}$ \\
\hline Synthetic mixture ${ }^{\dagger}$ & 5.0 & $\begin{array}{l}4.93,4.85,4.95 \\
\quad(\text { av. } 4.91 \pm 0.05)\end{array}$ \\
\hline
\end{tabular}

$\dagger$ The mixture consisted of $10 \mathrm{mg}$ of $\mathrm{Fe}, 44 \mathrm{mg}$ of $\mathrm{K}$, $38 \mathrm{mg}$ of $\mathrm{Mg}, 31 \mathrm{mg}$ of $\mathrm{Al}, 5 \mathrm{mg}$ of $\mathrm{Cu}, 7 \mathrm{mg}$ of $\mathrm{Zn}$, $0.2 \mathrm{mg}$ of $\mathrm{Ti}(\mathrm{IV}), 40 \mathrm{mg}$ of $\mathrm{Na}, 0.4 \mathrm{mg}$ of $\mathrm{Ca}, 0.1 \mathrm{mg}$ of $\mathrm{Mo}(\mathrm{VI})$ and $20 \mathrm{mg}$ of $\mathrm{H}_{3} \mathrm{PO}_{4}$.

Table 2 Determination of $\mathrm{Sn}$ in environmental standard reference materials $\dagger$

\begin{tabular}{|c|c|c|c|}
\hline Sample & $\begin{array}{l}\text { Sample taken/ } \\
\mathrm{g}\end{array}$ & $\begin{array}{c}\text { Sn content/ } \mathrm{R} \\
\mu \mathrm{g} \mathrm{g}^{-1}\end{array}$ & $\begin{array}{l}\text { Reported value/ } \\
\qquad \mathrm{g} \mathrm{g} \mathrm{g}^{-1}\end{array}$ \\
\hline \multirow[t]{4}{*}{ Pond Sediment } & 0.4891 & 11.1 & $12.6^{12)}$ \\
\hline & 0.4896 & 10.9 & \\
\hline & 0.4849 & 11.2 & \\
\hline & & av. $11.1 \pm 0.15$ & \\
\hline \multirow[t]{4}{*}{ Hair } & 1.5822 & 1.6 & $1.6^{13)}$ \\
\hline & 1.8416 & 1.5 & \\
\hline & 1.9790 & 1.6 & \\
\hline & & $1.6 \pm 0.06$ & \\
\hline \multirow[t]{5}{*}{ Mussel } & 1.9913 & 1.3 & $1.3^{14)}$ \\
\hline & 2.3546 & 1.6 & \\
\hline & 2.0534 & 1.9 & \\
\hline & 2.0700 & 2.1 & \\
\hline & & $1.7 \pm 0.35$ & \\
\hline
\end{tabular}

$\dagger$ Provided by National Institute for Environmental Studies
Table 2 に示す.これらについてはまだ報告された分析 值は少なく認証值も与えられていないが，既存の報告值 との一致はよく, 1〜10 ppm 程度の $\mathrm{Sn}$ が高い精度で 定量し得ることが示されている。

\section{交献}

1) G. Weber : Fresenius' Z. Anal. Chem., 321, 217 (1985).

2) Z. Marczenko : "Spectrophotometric Determination of Elements", (1976), (Ellis Horwood, Chichester).

3) F. D. Snell : "Photometric and Fluorimetric Methods of Analysis", Part I (1978), (John Wiley \& Sons, New York).

4) IUPAC, Applied Chemistry Division, Commission on Food Chemistry : Pure Appl. Chem., 54, 1737 (1982).

5) M. Koeva, S. Mareva, N. Jordanov : Anal. Chim. Acta, 75, 464 (1975).

6) M. Omar, H. J. M. Bowen : Analyst (London), 107, 654 (1982).

7）児玉幸雄, 坪田博行：分析化学, 20, 1554(1971).

8) 日本分析化学会編：“改訂三版 分析化学便覧”, p. 1218 (1981), (丸善).

9) 日本分析化学会編：“改訂三版 分析化学便覧”, p. 1241 (1981), (丸善).

10) F. W. E. Strelow, C. H. S. W. Weinert, C. Elott : Anal. Chem., 44, 2352 (1972).

11) H. J. M. Bowen : "Environmental Chemistry of the Elements", (1979), (Academic Press, London).

12) "Preparation, Analysis and Certification of Pond Sediment Certified Reference Material", Edited by K. Okamoto, (1982), (National Institute for Environmental Studies, Tsukuba).

13) "Analytical Results for NIES "Hair" Reference Material", (1986), (National Institute for Environmental Studies, Tsukuba).

14) “Analytical Results for NIES "Mussel" Reference Material", (1984), (National Institute for Environmental Studies, Tsukuba).

A combined anion-exchange/spectrophotometric method for the determination of traces of tin in environmental materials. Rokuro KURODA, Yutaka Hayashibe and Koichi Oguma (Laboratory for Analytical Chemistry, Faculty of Engineering, Chiba University, 1-33, Yayoi-cho, Chiba-shi, Chiba 260)

A combined anion-exchange/spectrophotometric method has been worked out for the determination of traces of tin in environmental materials. The sample is wet-ashed by a sulfuric acid-nitric acid mixture, if necessary, together with hydrofluoric acid. The tin is collected by anion-exchange on a Bio-Rad AG 1 $\left(\mathrm{SO}_{4}{ }^{2-}\right)$ column from $0.5 \mathrm{M}$ sulfuric acid-0.05 $\mathrm{M}$ oxalic acid solution. After washing the column with $3 \mathrm{M}$ hydrochloric acid- $1 \%$ ascorbic acid, the tin is eluted with $0.5 \mathrm{M}$ sulfuric acid- $0.3 \%$ hydrogen peroxide solution. The tin is subsequently determined spectrophoto- 
metrically with Pyrocatechol Violet. Results of the determination of tin in three environmental standard reference materials including Human Hair, Mussel and Pond Sediment are compiled. Relative standard deviations are in the range of $1 \%$ (for $10 \mathrm{ppm}$ level of tin) to $2 \sim 4 \%$ (for $1 \mathrm{ppm}$ level of tin).

(Received June 20, 1987)

\section{Keyword phrases}

anion-exchange of $\mathrm{Sn}(\mathrm{IV})$ in oxalate media; spectrophotometric determination of $\mathrm{Sn}$; trace analysis of environmental standard reference materials; oxalato complex of $\mathrm{Sn}$. 